\title{
PARAGANGLIOMA VAGAL - RELATO DE CASO E REVISÃO DA LITERATURA
}

\section{VAGAL PARAGANGLIOMA - CASE REPORT AND LITERATURE REVIEW}

Vinicius Ribas Fonseca1, Gustavo Bernardi2, Verônica Dalmas Padilha2, Laura Schwartz Maranho ${ }^{3}$, Guilherme Weiss Ribas ${ }^{3}$

\section{RESUMO}

Os paragangliomas (PG) são tumores raros, extremamente vascularizados, que se originam em células derivadas da crista neural associadas ao sistema nervoso autônomo. Relatamos um caso de paraganglioma vagal com embolização pré-operatória, seguida de exérese cirúrgica. Tendo como complicação a disfonia, devido a paralisia de prega vocal esquerda, e subsequente medicalização através de tireoplastia tipo 1 de Isshiki e fonoterapia.

Descritores: Paraganglioma vagal; paraganglioma; tumor de cabeça e pescoço

\section{ABSTRACT}

Paragangliomas (PG) are rare tumors, highly vascularized, which originate in derived neural crest cells associated with the autonomic nervous system. We report a case of vagal paraganglioma with preoperative embolization, followed by surgical excision, Having a complication dysphonia due to paralysis of the left vocal fold and subsequente medicalization through thyroplasty type 1 Isshiki and speech therapy.

Keywords: Vagal paraganglioma; paraganglioma; head and neck tumor

\author{
1. Coordenador da Especialização de ORL do Hospital da Cruz Vermelha Brasileira - Filial do \\ Estado do Paraná \\ 2. Especializando ORL do Hospital da Cruz Vermelha Brasileira - Filial do Estado do Paraná \\ 3. Médico graduado pela Universidade Positivo e pesquisador do Centro de Estudos \\ Otorrinolaringológicos Lauro Grein Filho
}

Contato do Autor / Mail to:

Vinicius Ribas Fonseca - vribasfonseca@gmail.com 


\section{INTRODUÇÃO}

Os paragangliomas são tumores raros, extremamente vascularizados, que se originam em células derivadas da crista neural associadas ao sistema nervoso autônomo.

Os paragangliomas vagais (PV) tem origem, em sua maioria, no gânglio nodoso inferior e são geralmente benignos. São considerados neoplasias raras e representam menos de $2,5 \%$ de todos os paragangliomas localizados na cabeça e pescoço.

O objetivo deste trabalho é fazer a descrição de um caso de paraganglioma vagal com embolização préoperatória, seguida de cirurgia para exérese. Tendo como complicação a disfonia, devido a paralisia de prega vocal esquerda, o paciente se beneficiou com a tireoplastia tipo 1 de Isshiki.

\section{RELATO DE CASO}

A.Z., 54 anos, masculino, casado, trabalhador de uma agência de correios, natural e procedente de Curitiba, procura serviço de Oncologia devido a tumor cervical esquerdo na face medial do músculo esternocleidomastoídeo, sem outras queixas. Ao exame físico, tumoração de consistência macia e elástica, indolor, medindo cerca de $05 \mathrm{~cm}$. A ultrassonografia cervical mostrou hipervascularização, tamanho aproximado de 05 $\mathrm{cm}$, sendo puncionado e tendo como resultado citológico fundo hemático e raros linfócitos. Material inconclusivo para diagnóstico. Solicitado tomografia computadorizada (TC) com contraste: provável tumor do glomus vagal ou paraganglioma. Após, foi solicitado angiotomografia (angioTC), afim de avaliar possível envolvimento de carótidas, definição do tumor e irrigação. Além de complementar o diagnóstico, o exame permite avaliar os riscos de sequelas pós operatórias.

AngioTC (figuras 1 e 2): lesão expansiva situada no espaço carotídeo esquerdo, determinando descolamento anterior das artérias carótidas interna e externa. A lesão é caracterizada por intenso realce já na fase arterial, associado a pequenas áreas hipodensas no seu interior que podem representar focos de degeneração e/ou necrose. A massa mede cerca de $50 \times 32 \times 27 \mathrm{~mm}$ dos seus maiores diâmetros caudal, anteroposterior e transverso, respectivamente. Não há sinais de invasão de estruturas vasculares pela lesão. Observa-se somente compressão da veia jugular interna esquerda. Os aspectos de imagem sugerem como primeira hipótese a possibilidade de paraganglioma vagal. Solicitado embolização pré-operatória, sendo realizada em ramos da artéria faríngea ascendente esquerda, artéria lingual e sua porção proximal, ramos da artéria língua esquerda, sendo que o controle angiográfico evidenciou a exclusão de quase a totalidade da lesão quando comparado as imagens iniciais.
Realizado exérese do tumor (paraganglioma vagal esquerdo) e linfonodo cervical esquerdo, sendo estes enviados para anatomopatológico e tendo como achados: segmento lobulado, recebida já seccionado, de tecido castanho-vinhoso, despolido e fosco, medindo 5,0 x 3,0 x $2,0 \mathrm{~cm}$. Aos cortes, tecido de aspecto poroso, com cavidades císticas preenchidas por pequenos cistos hemorrágicos, parece castanho-acinzentadas, firmes e elásticas. Estrutura nodular $2,5 \times 1,8 \times 0,8 \mathrm{~cm}$. Diagnóstico: paraganglioma (arterite com oclusão vascular por êmbolos) e linfonodo preservado (alguns vasos embolizados).

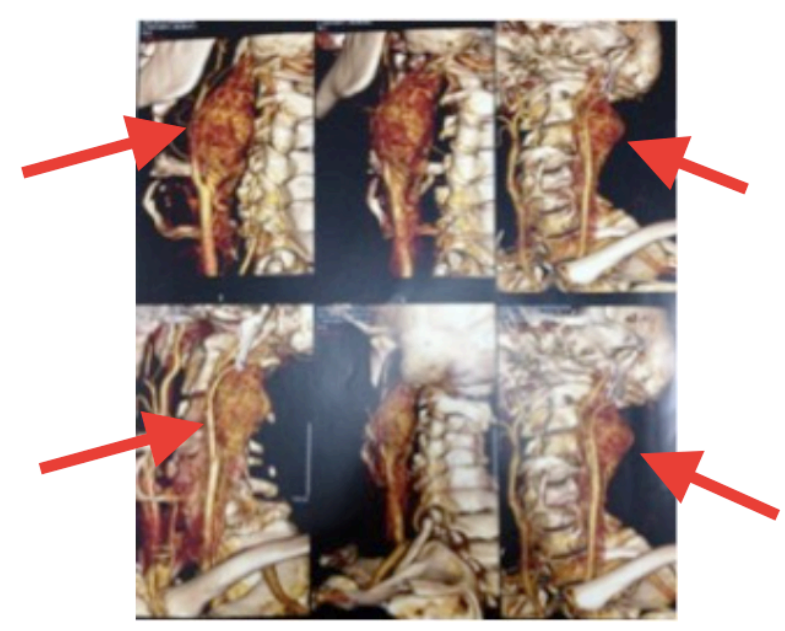

Figura 1. Angiotomografia computadorizada tridimensional

Ao retornar 20 dias após a cirurgia, apresenta como queixas disfonia, engasgos, dor em ferida operatória, hiperemia discreta e pequena coleção local. Tem-se como hipótese o seroma, sendo optado por utilizar antiinflamatório não esteroidal (AINE) e acompanhamento, apresentando boa evolução do quadro.

Encaminhado para fonoterapia, devido as queixas de cansaço ao falar, além de aumento de saliva durante a fala e afogamento com água. Pela fonoaudiologia: qualidade vocal - rouca/soprosa grau moderado a severo. Devido a persistente quadro disfônico, o paciente foi submetido a videolaringoscopia pela equipe de Otorrinolaringologia, afim de lucidar possível diagnóstico de paralisia de prega vocal esquerda.

Durante 3 meses de fonoterapia não houve melhora do quadro, sendo então encaminhado novamente a Otorrinolaringologia, pois a prega vocal direita atingiu o seu limite em termos de coaptação. Após avaliação, foi optado por realizar tireoplastia tipo 1 de Isshiki indicada neste caso. Foi realizada ressecção de fração de cartilagem tireoide para acesso a prega vocal, laringoscopia de suspensão para controle cirúrgico, colocação de fitas confeccionadas com 0 patch de politetrafluoroetilena expandido (ePTFE), Gore-Tex® lateralmente a prega vocal esquerda e a seguir medialização de prega vocal esquerda confirmada pela 
laringoscopia de suspensão. Após avaliação pós operatória, o paciente reiniciou a fonoterapia pós tireoplastia. Hoje, um mês após, o paciente apresenta voz limpa e sonora, mantendo acompanhamento fonoaudiológico.

\section{DISCUSSÃO}

A maioria dos tumores da cabeça e pescoço surgem da bifurcação da artéria carótida. Os paragangliomas vagais (PV) surgem da parte autonômica do nervo vago ( $X$ par craniano), no gânglio nodoso inferior. Os sintomas dependem da localização do tumor ao longo do nervo vago, desde a base do crânio até a parte inferior do pescoço, mas os mais frequentes são massa cervical (74\%) e disfonia $(37 \%)^{1,2,3}$. Outros sintomas são zumbido pulsátil e em menos de $50 \%$ dos paragangliomas há déficits dos nervos vago, hipoglosso, glossofaríngeo e acessório ${ }^{2-4}$. Extensão intracraniana, a qual é a principal causa de óbito, pode ocorrer em $22 \%$ dos casos 5 .

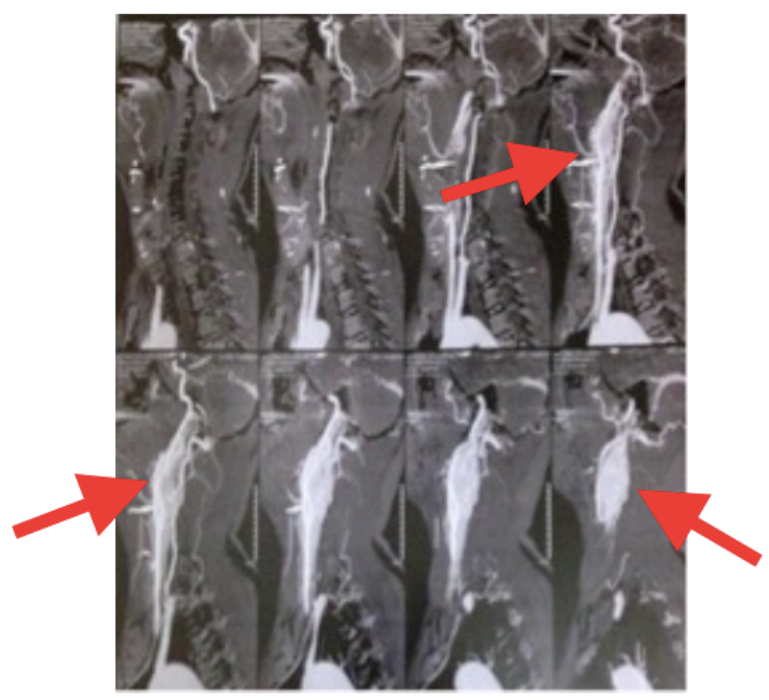

Figura 2. Angiotomografia computadorizada

O tratamento é fundamentalmente cirúrgico e inclui a exérese do tumor primária e possíveis metástases linfonodais ${ }^{3}$. Se a remoção cirúrgica for bem sucedida, o controle local do tumor pode ser alcançado em até $100 \%$ dos casos.

Disfunção do nervo vagal é uma das principais complicações pós operatórias, pois na maioria dos casos é necessária a remoção cirúrgica. A taxa de complicações cirúrgicas nos PV aumenta com o tamanho do tumor. As consequências imediatas seriam rouquidão, disfagia e aspiração. Quando há lesão dos pares IX, XI e XII, podem ocorrer sintomas como ombro caído, refluxo nasal de fluidos e hemiatrofia da língua ${ }^{1}$. Deve-se lembrar que a morbidade de uma paralisia de nervos cranianos causados pela cirurgia é maior do que a morbidade causada pela perda lenta da função nervosa através do tumor. Assim, a remoção cirúrgica dos PV deve ser ponderada, considerando a idade do paciente, o tamanho do tumor, velocidade de crescimento do tumor e a função dos nervos cranianos $^{2}$. Zanoletti, em seu estudo, afirma que a morbidade cirúrgica associada ao déficit vagal é inevitável. Suas experiências demonstraram que a função vagal não pode ser preservada mesmo quando o nervo é mantido anatomicamente intacto ${ }^{6}$.

As causas de paralisia das pregas vocais podem ser divididas em origem central (neuropatia vagal, como o PV) e periférica (neuropatia do nervo laríngeo recorrente), sendo a última mais comum, chegando a até $90 \%$ dos casos em algumas séries. Porém, na maioria dos casos (até 85\%) não se identificam lesões ao longo do trajeto dos nervos?.

Os procedimentos cirúrgicos descritos para restaurar a mobilidade da prega vocal paralisada não apresentaram resultados satisfatórios. Assim, o tratamento cirúrgico mais comumente usado é direcionado para o reposicionamento da prega vocal na posição média. A medialização da corda vocal (tireoplastia tipo I de Isshiki) permite um fechamento glótico mais adequado, facilitando a produção vocal. Três técnicas cirúrgicas são fundamentalmente utilizadas na atualidade: (1) injeção de prega vocal, (2) adução de aritenoide e (3) laringoplastia medializadora ou tireoplastia tipo I.

A técnica utilizada no caso descrito foi a tireoplastia tipo I, que, por meio de uma cervicotomia com anestesia local, consiste na confecção de uma janela na cartilagem tireóidea do lado acometido com introdução de um implante (ePTFE). Com o molde, desloca-se a prega vocal para uma posição mais mediana e, por ser realizada sob anestesia local, a técnica permite um ajuste intraoperatório da voz ${ }^{8}$. Dentre as vantagens do ePTFE em relação à materiais como o silicone e Teflon, podemos citar: (a) não necessitam de materiais especiais, (b) não há necessidade de precisão na criação da janela na cartilagem tireóidea, (c) a posição ideal para colocação do enxerto pode ser facilmente alcançada durante a cirurgia, (d) apresenta uma experiência longa de uso e um índice de complicações muito baixo e (e) parece-nos, pela pequena experiência inicial, que diminui a necessidade de realização de adução de aritenoide, por conseguirmos um bom posicionamento do implante. Os resultados desta técnica estão diretamente relacionados à abertura da janela na cartilagem tireóidea na posição correta9.

O paciente é mantido em completo repouso vocal e tratado com antibióticos durante uma semana. 0 edema de prega vocal normalmente dura de duas a três semanas, período no qual a voz fica áspera. Uma qualidade vocal muito boa nesse período de pós-operatório pode ser indicativo de que alguma deterioração vocal ocorrerá com a regressão do edema 9 .

\section{CONCLUSÃO}

Diante do diagnóstico de paraganglioma, o tratamento preconizado é o cirúrgico podendo ou não ser precedido de embolização. Entre as complicações 
cirúrgicas, as lesões nervosas estão entre as mais comuns, ocorrendo em torno de $40 \%$ dos casos. Havendo como complicação a paralisia unilateral de prega vocal, a tireoplastia tipo I se tornou o procedimento de escolha para o retorno da qualidade vocal.

\section{REFERÊNCIAS}

1. Tratado de Otorrinolaringologia e Cirurgia Cervicofacial. Vol 4. 2a edição, 2011.

2. Offergeld C, Brase C, Yaremchuk S, Mader I, Rischke $\mathrm{HC}$, Glasker S, et al. Head and Neck paragangliomas: clinical and molecular genetic classification. Clinics. 2012;67(S1):19-28.

3. Pinto FR, Scarpa MB, Kanda JL, Correa JA, Zeibil DK. Paraganglioma vagal maligno. Rev. Bras. Cir. Cabeça Pescoço, v. 37, n 2, p. 122-123, abril/maio/junho 2008.

4. Koishi HU et col. Paraganglioma cervical bilateral. Arquivos Internacionais de Otorrinolaringologia, 1998, vol 2, num 3, julho/setembro.

5. Caldarelli C, Iacconi C, Della Giovampaola C, lacconi P, Beatrice F. Vagal paragangliomas: two case reports. Acta Otorhinolaryngol Ital. 2007 Jun;27(3): 139-143.

6. Zanoletti E, Mazzoni A. Vagal paraganglioma. Skull Base. 2006;(3):161-7.

7. Garcia MM, Magalhães FP, Dadalto GB, Moura MVT. Avaliação por imagem da paralisia de pregas vocais. Radiol Bras. 2009;42(5):321-326.

8. Ganança FF, Ponte P. Manual de Otorrinolaringologia e Cirurgia de Cabeça e Pescoço. Editora Manole, $1^{a}$ edição, 2011, p 71.

9. Sant `Anna GD, Maur M. Laringoplastia medializadora com politetrafluoroetileno expandido (ePTFE) (GoreTex®). Revista Brasileira de Otorrinolaringologia. Vol 67, 3a edição, maio/junho, 2001. 